\title{
Crucial Occupations during the Covid-19 Pandemic: Wage Trends leading up to the Pandemic in the Netherlands
}

Christoph Janietz ${ }^{1} \quad$ Herman G. van de Werfhorst ${ }^{2}$

1 University of Amsterdam, The Netherlands (c.janietz@uva.nl)

2 University of Amsterdam, The Netherlands (h.g.vandewerfhorst@uva.nl)

Working Paper, October 28, 2020

\begin{abstract}
:
In March 2020, the Dutch government defined a set of occupations that were designated as crucial for maintaining the basic functioning of society during the Covid-19 pandemic. A central question in the current public debate on work and pay is whether workers in crucial occupations have been sufficiently remunerated for their work over the past years. Using a combination of the Dutch labor force survey and register data during the period 2006-2019, we find that the wages of workers in crucial occupations have on average improved over time relative to the wages of workers in other occupations, although this development has stalled in recent years. At the same time, workers in crucial occupations earn less relative to comparable workers in other occupations within several industries, while they often earn more within major occupational groups. The analysis also reveals substantial heterogeneity in wage gaps and their trends across industries. We conclude by formulating some preliminary thoughts on the potential long-term consequences of the Covid-19 pandemic on the relationship between occupations and wages.
\end{abstract}

*This research was funded by a ZonMW grant under the title "De maatschappelijke dynamiek van de COVID-19 pandemie: onderwijs, sociaal-economische positie en solidariteit.”. 


\section{Introduction}

At the end of March 2020, the Dutch government issued a list of occupations that were designated as crucial for maintaining the basic functioning of society during the Covid-19 pandemic. In order to focus on their jobs that are often associated with an increased risk of infection (Mutambudzi et al. 2020), workers in crucial occupations were allowed to send their children to childcare services and schools. For the rest of the population, childcare facilities remained closed to ensure a slowdown of viral transmission.

The designation of crucial occupations by the government as a response to the Covid19 pandemic has since entered the public debate on work and pay. A central question is whether workers in such occupations have been sufficiently remunerated for their work over the past years. Only recently in September 2020, the Dutch federation of trade unions FNV demanded a 5\% pay raise specifically for workers in crucial occupations. Likewise, a motion asking for a structural pay increase for health workers was brought forward in parliament. However, this initiative was vetoed by the governing parties, a decision that was defended by the Minister of Public Health on the grounds of recent pay rises in the health sector.

Besides the health sector, it is unknown how the labor market conditions of a broader set of crucial occupations have developed during the past years. From a structural-functionalist perspective, occupations are rewarded according to their 'functional necessity' (Davis and Moore 1945). However, the functional importance of certain occupations during the times of a pandemic was not necessarily acknowledged while setting labor agreements before 2020 .

Other theories have emphasized that wage distributions are shaped by negotiation processes that involve the exercise of bargaining power (Tomaskovic-Devey and Avent-Holt 2018). The occupational literature argues that existing power differentials among occupations do not merely reflect an objective hierarchy of functional importance but are rather shaped by broader shared values and beliefs in society that are anchored around specific criteria like 
academic knowledge (Zhou 2005). Instead, occupational groups derive bargaining power based on processes of professionalization and credentialing that increase the legitimacy of their claims as a group (Abbott 1988; Vallas 2001). Also from this second perspective, it is not necessary that existing power differences before the pandemic would have resulted in wage outcomes that favor the crucial occupations given that they can be found throughout the established occupational hierarchy reaching from the professions to the elementary occupations.

In this article, we trace the wages of workers in crucial occupations during the years preceding the Covid-19 pandemic (2006-2019). We analyze yearly wage gaps in detail broken down by industry and major occupation groups. Studying these wage trends allows us to assess the financial rewards of crucial occupations until the start of the pandemic, and helps us to put public claims for better working conditions of workers in crucial occupations into perspective. As the overall impact of the Covid-19 pandemic on occupational wages are not yet fully foreseeable, we conclude by formulating some preliminary thoughts on potential long-term consequences.

\section{Data and Methods}

\subsection{Data and sample}

We use a combination of the Dutch Labor Force Survey (Enquete Beroepsbevolking, (EBB)) and Dutch register data for the period between 2006 to 2019. We limit the EBB sample to the first observation of each respondent upon entering the rotating panel. By doing so, we set up a repeated cross-section with a changing sample of respondents from year to year.

We supplement the EBB with wage data stemming from the Dutch tax registers. The analysis focuses on the main job of a person that is defined as the job with the most hours worked at the time of the survey. We aggregate all wages and hours for each main job over the full calendar year to limit distortions based on the seasonality of additional bonus payments. 
We restrict the sample to workers between the age of 16 and 65, and exclude respondents working in the armed forces and extraterritorial organizations. The final weighted sample comprises 686,539 observations. The yearly survey weights of the EBB are applied throughout the entire analysis, but are rescaled to ensure equal weight of each year independent of the yearly sample size.

\subsection{Variables}

The dependent variable in our analysis is the logged hourly nominal wage of a respondent. Our wage measure contains all bonus payments on top of the base wage, but does not include overwork compensation and -hours. We do not adjust for inflation as our main focus in the analysis is on year-specific wage gaps between workers in crucial occupations relative to other workers.

Our key independent variable is a dummy variable that identifies persons who work in a crucial occupation. This measure is based on the list of crucial occupations that was published by the Dutch government at the end of March 2020. We rely on two occupational classification schemes (ISCO08 and the Dutch BRC 2014) as well as one industry classification scheme (the Dutch SBI 2008) to designate the status of working in a crucial job.

Two important clarifications concerning our measure are warranted. First, the identification is solely based on the list of crucial occupations published by the Dutch government. We do not make own judgements concerning the relative importance of occupations within the Dutch society. Instead we adopt the judgement of the Dutch government as an institution, whose decisions not only carry real-life consequences in terms of actual regulations during the times of the Covid-19 pandemic (e.g. who is required to go to the workplace), but might also influence how citizens judge the importance of work done by specific occupations in the future. Second, a definitive translation of the government list is 
difficult to accomplish. The list denotes broad job descriptions that do not always correspond neatly to the categories in the occupational classification schemes. We provide the translated government list and our coding scheme as an additional appendix for interested readers to ensure transparency of our coding decisions.

We control for several individual-level variables that are potential confounders in the relationship between crucial occupations and wages. These controls comprise gender, age, migration background, level of education, type of household, and the presence of a child (0-18 years old) in the same household. Age is included as a linear and quadratic term in the models. In addition, we draw on the first digit level of the SBI (20 industry categories) and the ISCO08 (9 major occupation groups) to differentiate more detailed labor market segments.

\section{$2.3 \underline{\text { Analytical strategy }}$}

We adopt two distinct lenses to trace wage gaps between workers in crucial occupations and other occupations during 2006 to 2019 . The first is a within-industry perspective. Here we contrast the wages of workers in crucial occupations to other workers located in the same industry. The underlying idea is that existing within-industry wage penalties for workers in crucial occupations can be problematized (disregarding their occupational class position) given that their work has been acknowledged as an important factor in maintaining the basic functioning of society during the times of the Covid-19 pandemic.

The second is a within-occupational class perspective. In this approach, we take for granted an established underlying hierarchy of occupational groups. Instead, we focus on whether it pays off to work in a crucial occupation compared to working in another occupation within the same strata of the occupational hierarchy (e.g. among professionals).

To give an example, supermarket cashiers have been designated as a crucial occupational group. Their work contributed to the continued distribution of food among the 
population while being exposed to a heightened risk of infection at their workplace. Although they might earn a lower wage than workers in other occupations within the wholesale and retail trade industry (within-industry perspective), they can still receive a pay premium relative to workers in other occupations among the service and sales workers (within-occupational class perspective).

We use OLS regression models to trace wage gaps between workers in crucial and other occupations. Throughout, we focus on reporting the estimated yearly marginal effects of working in a crucial occupation on the log hourly wage.

\section{3. $\quad \underline{\text { Results }}$}

\section{[Table 1 about here]}

In table 1, we break down all covariates by the two groups of crucial and other occupations to get a better idea of their composition. In general, the composition of both groups is fairly similar when it comes to the individual-level controls. Most pronounced is the difference in the gender composition. Female workers make up more than $60 \%$ of the workers in the crucial occupations compared to around $40 \%$ of female workers in the other occupations. Looking at wages, there is a raw average wage gap of $1.52 € / \mathrm{h}$ between the two groups. The within-group variation in hourly wages is larger among the other occupations, where exceptionally high wages are more common.

\subsection{Overall marginal effects of working in a crucial occupation on wages}

[Figure 1 about here]

In a first step, we start our analysis with an assessment of average wage gaps across all industries and major occupation groups (figure 1). Looking at the first model, there is an estimated persistent wage penalty for working in a crucial occupations that ranges from around 
$-1 \%$ to $-2 \%$. When adjusting for the individual-level control variables, we find a reversive pattern. An initial wage penalty at the start of the observation period (around $-2 \%$ ) turns into a wage premium in the latter years up to a magnitude of around $+4 \%$.

The importance of the distinction between a within-industry and within-occupation group perspective becomes clear when looking at model 3 and 4. Based on model 3, when accounting for industry composition, we find a wage penalty that amounts to up to $-5 \%$ in the early years but is not statistically significantly different from 0 between 2014 to 2016 . In contrast, based on model 4 in which we control for major occupation groups, we find a persistent wage premium that reaches up to $+6 \%$ in 2016 . On aggregate, workers in crucial occupations earn less than comparable workers in other occupations within the same industry, but earn more relative to comparable workers in other occupations within the same major occupation group.

Noteworthy is also the overall time trend of the aggregate wage gap. Between 2006 and 2014, the wages of workers in crucial occupations continuously improve relative to workers in other occupations. After 2014, this trend stalls and even slightly reverses starting with 2017.

\subsection{Marginal effects of working in a crucial occupation on wages by industry}

\section{[Figure 2 about here]}

In a second step, we analyze the yearly wage gaps individually by industry. ${ }^{1}$ Looking at the estimates of model A, we find a statistically significant wage gap in ten out of the 20 industries. Among those industries are the wholesale and retail trade as well as the education sector (both around -2 to $-3 \%$ ). The largest wage gaps are found within the industries of agriculture (around

\footnotetext{
${ }^{1}$ We model heterogenous wage gaps and time trends across industries by specifying a three-way interaction term between the crucial occupation indicator, the time variable, and the industry categories. We resort to modelling a linear time trend to ensure a large enough number of observations per estimate.
} 
$-10 \%$ ) and waste management (around -15\%). In contrast, we find a wage premium for workers in crucial occupations within five industries, among them mining and quarrying (around $+10 \%$ to $+30 \%$ ) as well as human health (around $+10 \%$ to $+15 \%$ ). When considering trends over time, there are several industries in which the predicted wage penalty of working in a crucial occupation has grown over time. This includes among others the industries of transportation (from around $-2 \%$ to $-3 \%$ ) and public administration (from around $-1 \%$ to $-5 \%$ ). In other industries, the wage gap has become smaller over time as visible in the construction (from around $-12 \%$ to $-2 \%$ ) and manufacturing industry (from around $-9 \%$ to $-5 \%$ ).

In model $\mathrm{B}$, we control additionally for major occupation groups to trace in how far wage gaps within industries are related to the composition of groups in terms of occupational classes. With the sole exception of the education sector, all initially estimated industry-specific wage penalties are largely accounted for when controlling for the major occupation groups. For example, the wage penalty of working in a crucial occupation within the waste management industry is fully explained by those workers being more strongly concentrated in, on average, lower-paid segments of the occupational hierarchy.

\subsection{Marginal effects of working in a crucial occupation on wages by industry}

\section{[Figure 3 about here]}

In a last step, we trace the yearly wage gaps by each major occupation group. ${ }^{2}$ Based on model $\mathrm{C}$, we find a wage premium for working in a crucial occupation within three of the nine major occupation groups. Working in a crucial occupation pays off within the groups of clerical support workers (around $+6 \%$ ), services and sales workers (around $+17 \%$ to $+22 \%$ ), and elementary occupations (around $+6 \%$ to $+7 \%$ ). Within other major occupational groups there is a reversive pattern. An initial wage penalty becomes smaller over time and even turns into a

\footnotetext{
${ }^{2}$ We employ a similar modelling approach as in section 3.2. The sole difference is that we swap the role of the major occupation group and industry indicator.
} 
wage premium among managers (from around $-7 \%$ to $+4 \%$ ) and the professions (from around $-7 \%$ to $+1 \%$ ). A persistent wage penalty can be found among technicians (from around $-4 \%$ to $-1 \%$ ) and craft workers (around $-4 \%$ throughout).

Looking at model D, we find that group differences in the composition by industry partially account for the wage premium of workers in crucial occupations among the service and sales workers and the elementary occupations. Within these two major occupation groups, workers in crucial occupations earn higher wages than workers in other occupations partly because they are located in comparatively well-paying industries. Among the professionals, the composition by industries explains a substantial part of the initial wage penalty for workers in crucial occupations.

\section{Discussion}

To summarize, the wages of workers in crucial occupations have on average improved over time relative to the wages of workers in other occupations, although this development has stalled in recent years. While workers in crucial occupations earn less than comparable workers of other occupations inside several industries, they often earn more within several major occupation groups. At the same time, the analysis reveals substantial heterogeneity in wage gaps and their trends particularly across industries.

While the overarching impact of the Covid-19 pandemic on the wages of occupations is not yet fully foreseeable, there is room to theorize on potential consequences. Considering the socio-economic hierarchy of occupations, Parkin (1971, p.42) claimed that "certain criteria become institutionalized as 'relevant' for ranking purposes, $[. .$.$] ”' and "once a given set of rank$ criteria has been successfully legitimized throughout society, then the main lines of the status order will have been laid down". The experience of the Covid-19 pandemic and the subsequent government response of designating certain occupations as crucial may lead to a reconfiguration 
of those criteria. The questions of whether the Covid-19 pandemic will cause an increase in relative wages of workers in crucial occupations and whether this will diminish (withinindustry) wage gaps between established strata of the occupational hierarchy should be on the agenda for future research in the field of social stratification.

\section{Funding Acknowledgement}

This research was funded by a ZonMW grant under the title "De maatschappelijke dynamiek van de COVID-19 pandemie: onderwijs, sociaal-economische positie en solidariteit.”. 


\section{$\underline{\text { References }}$}

Abbott, Andrew. 1988. The System of Professions: An Essay on the Division of Expert Labor. Chicago: The University of Chicago Press.

Davis, Kingsley, and Wilbert E. Moore. 1945. 'Some Principles of Stratification'. American Sociological Review 10(2):242-49. doi: 10.2307/2085643.

Mutambudzi, Miriam, Claire L. Niedzwiedz, Ewan B. Macdonald, Alastair H. Leyland, Frances S. Mair, Jana J. Anderson, Carlos A. Celis-Morales, John Cleland, John Forbes, Jason MR Gill, Claire Hastie, Frederick K. Ho, Bhautesh D. Jani, Daniel F. Mackay, Barbara I. Nicholl, Catherine A. O’Donnell, Naveed I. Sattar, Paul I. Welsh, Jill P. Pell, Srinivasa Vittal Katikireddi, and Evangelia Demou. 2020. 'Occupation and Risk of Severe COVID-19: Prospective Cohort Study of 120,075 UK Biobank Participants'. MedRxiv 2020.05.22.20109892. doi: 10.1101/2020.05.22.20109892.

Parkin, Frank. 1971. Class Inequality and Political Order: Social Stratification in Capitalist and Communist Societies. London: MacGibbon \& Kee.

Tomaskovic-Devey, Donald, and Dustin Robert Avent-Holt. 2018. Relational Inequalities: An Organizational Approach. New York: Oxford University Press.

Vallas, Steven Peter. 2001. 'Symbolic Boundaries and the New Division of Labor: Engineers, Workers and the Restructuring of Factory Life'. Research in Social Stratification and Mobility 18:3-37. doi: 10.1016/S0276-5624(01)80021-4.

Zhou, Xueguang. 2005. 'The Institutional Logic of Occupational Prestige Ranking: Reconceptualization and Reanalyses'. American Journal of Sociology 111(1):90-140. doi: $10.1086 / 428687$. 


\begin{tabular}{|c|c|c|c|}
\hline & & $\begin{array}{c}\text { Other } \\
\text { Occupations }\end{array}$ & $\begin{array}{c}\text { Crucial } \\
\text { Occupations }\end{array}$ \\
\hline \multicolumn{4}{|l|}{ Hourly wages } \\
\hline & Mean & $21.02 €$ & $19.50 €$ \\
\hline & SD & 22.17 & 10.88 \\
\hline \multicolumn{4}{|l|}{ Individual-level controls: } \\
\hline \multicolumn{4}{|l|}{ Age } \\
\hline & Mean & 39.33 & 39.57 \\
\hline & SD & 12.54 & 13.14 \\
\hline \multicolumn{4}{|l|}{ Gender } \\
\hline & Female & $40.83 \%$ & $60.95 \%$ \\
\hline \multicolumn{4}{|l|}{ Migration Background } \\
\hline & 1st generation & $10.36 \%$ & $8.33 \%$ \\
\hline & 2nd generation & $8.79 \%$ & $7.85 \%$ \\
\hline \multicolumn{4}{|l|}{ Education } \\
\hline & Low & $23.13 \%$ & $21.15 \%$ \\
\hline & Medium & $43.20 \%$ & $43.75 \%$ \\
\hline & High & $33.67 \%$ & $35.10 \%$ \\
\hline \multicolumn{4}{|l|}{ Household position } \\
\hline & Single household & $15.73 \%$ & $14.08 \%$ \\
\hline & Single parent & $3.27 \%$ & $4.41 \%$ \\
\hline & Cohabiting parents & $40.83 \%$ & $41.18 \%$ \\
\hline & Cohabiting with partner & $25.94 \%$ & $25.69 \%$ \\
\hline & Other & $14.24 \%$ & $14.65 \%$ \\
\hline \multicolumn{4}{|l|}{ Child (0-18) in household } \\
\hline & Yes & $44.22 \%$ & $46.25 \%$ \\
\hline \multicolumn{4}{|l|}{ ISCO Major Groups } \\
\hline & Managers & $8.24 \%$ & $1.50 \%$ \\
\hline & Professionals & $22.12 \%$ & $26.94 \%$ \\
\hline & Technicians and Associate Professionals & $16.46 \%$ & $18.79 \%$ \\
\hline & Clerical Support Workers & $12.75 \%$ & $9.06 \%$ \\
\hline & Services and Sales Workers & $16.64 \%$ & $23.81 \%$ \\
\hline & $\begin{array}{l}\text { Skilled Agricultural, Forestry, and Fishery } \\
\text { Workers }\end{array}$ & $0.03 \%$ & $2.67 \%$ \\
\hline & Craft and Related Trades Workers & $12.44 \%$ & $1.52 \%$ \\
\hline & Plant and Machine Operators and Assemblers & $4.51 \%$ & $4.98 \%$ \\
\hline & Elementary Occupations & $6.81 \%$ & $10.74 \%$ \\
\hline \multicolumn{4}{|l|}{ Industry (SBI 1st digit) } \\
\hline & A Agriculture, Forestry, and Fishing & $0.74 \%$ & $2.01 \%$ \\
\hline & B Mining and Quarrying & $0.11 \%$ & $0.21 \%$ \\
\hline & C Manufacturing & $15.13 \%$ & $3.94 \%$ \\
\hline & $\begin{array}{l}\text { D Electricity, Gas, Steam and Air Conditioning } \\
\text { Supply }\end{array}$ & $0 \%$ & $1.29 \%$ \\
\hline & $\begin{array}{l}\text { E Water Supply; Sewerage; Waste Management } \\
\text { and Remediation Activities }\end{array}$ & $0.53 \%$ & $0.48 \%$ \\
\hline
\end{tabular}




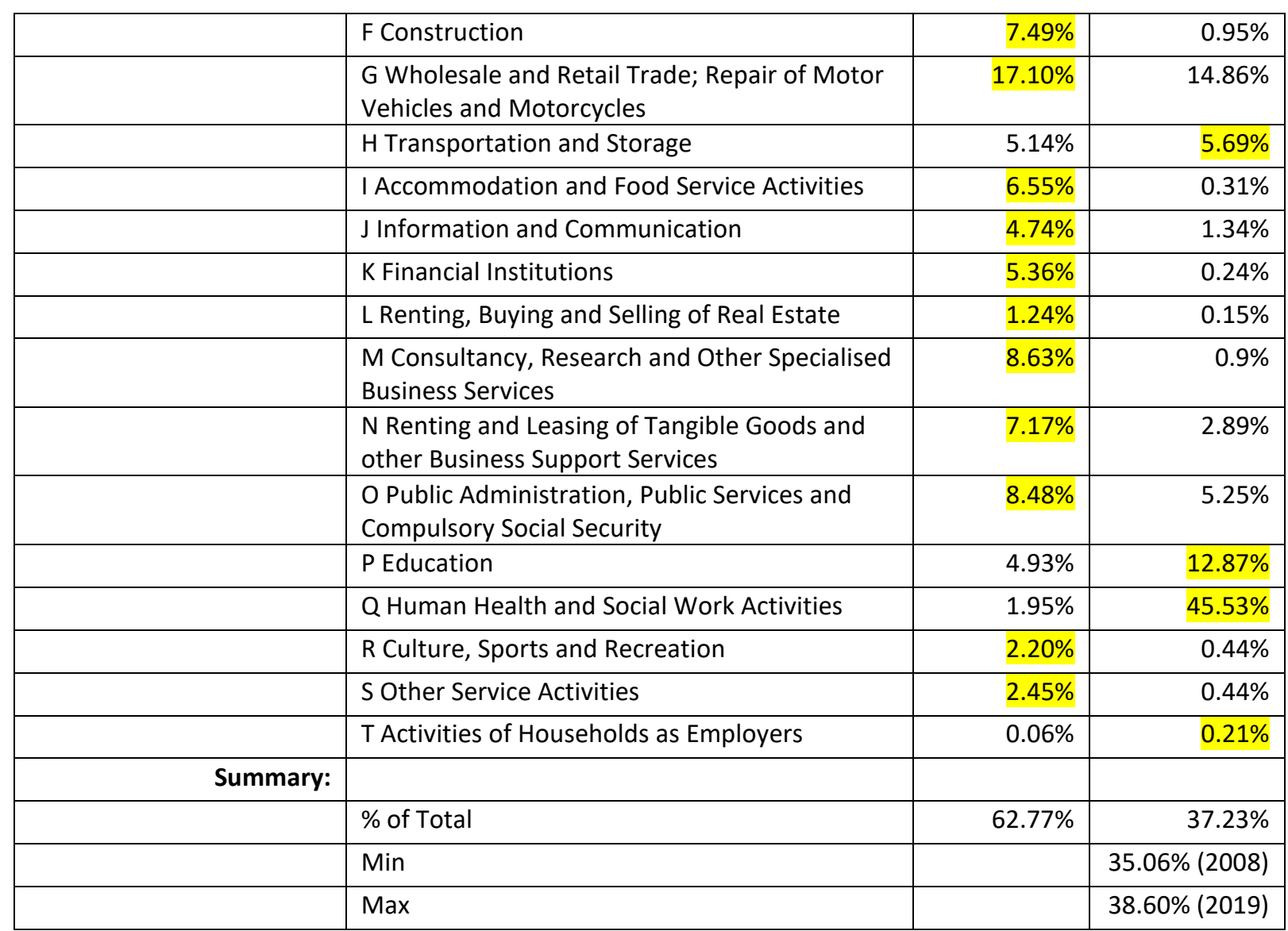

Table 1 - Descriptive statistics of the sample by crucial occupation status (2006-2019)

(Note: Sample includes all main jobs of dependent employed workers aged 16-65. Main jobs are defined as the job with the most hours worked at the time of the survey. Reported percentages refer to within-group proportions. Survey weights are applied.) 


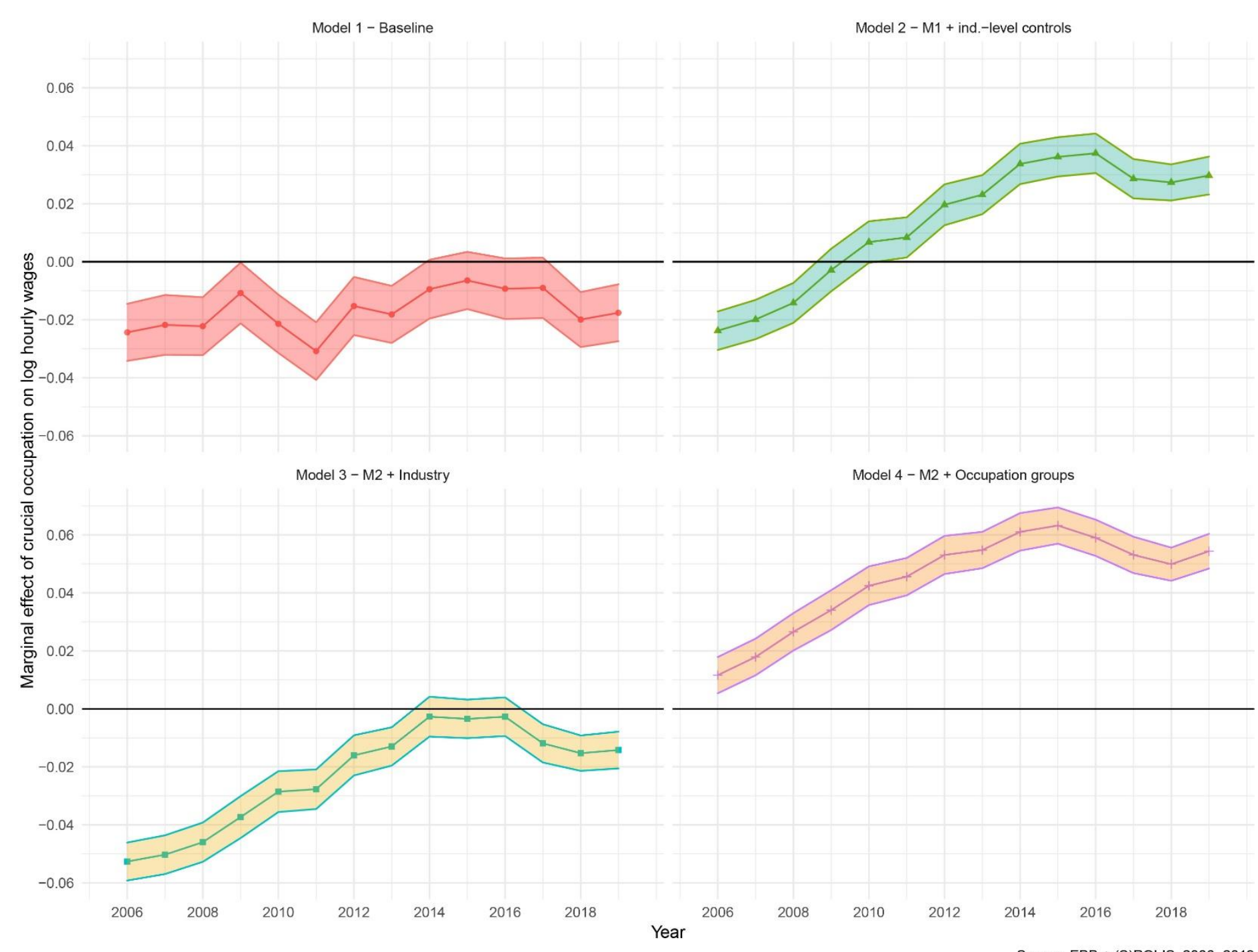

Figure 1 - Marginal effects of crucial occupations on log hourly wages by industry

(Note: Estimates are based on linear regression models. Model 1 includes a two-way interaction between the crucial occupation identifier and year categories. In Model 2 all individual-level controls as described in section 2.2 are included. Model 3 controls additionally for industry and Model 4 for major occupation groups. 


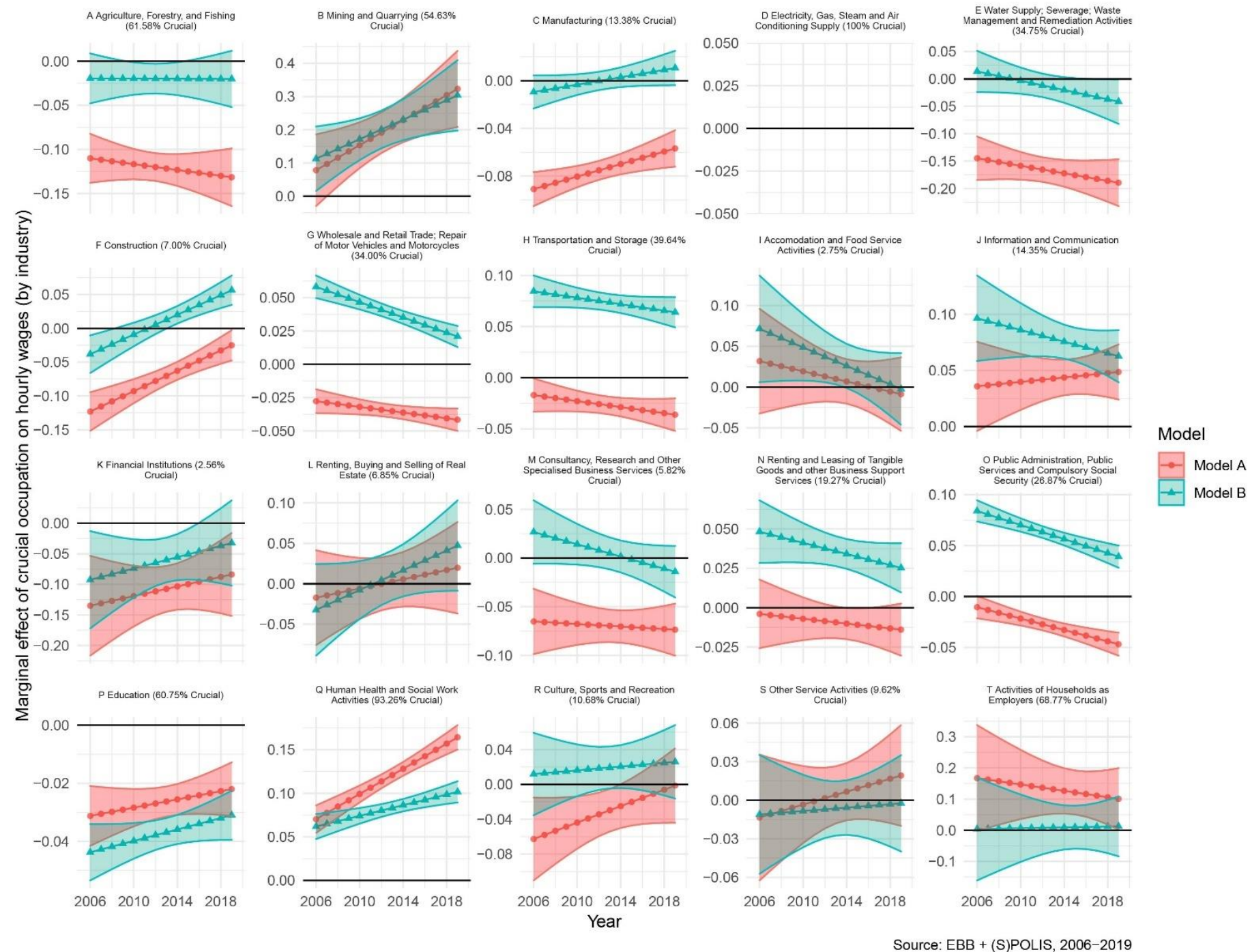

Figure 2 - Marginal effects of working in a crucial occupation on log hourly wages by industry

(Note: Estimates are based on linear regression models. Model A includes all individual-level controls and a three-way interaction between the crucial occupation dummy, the industry categories, and year as a continuous variable. We model linear time trends to ensure a sufficient number of observations per estimate. Model B controls additionally for ISCO08 major groups.) 


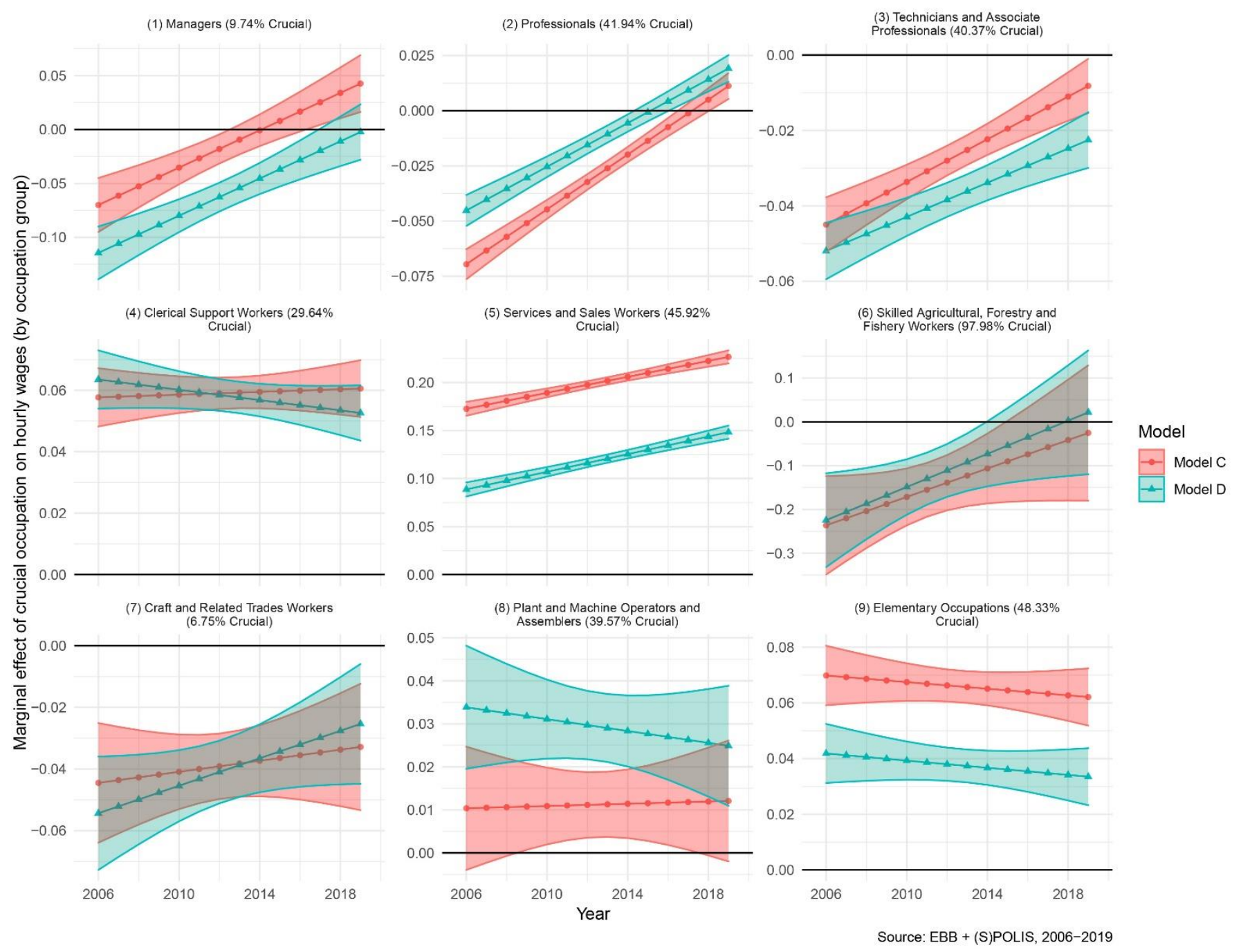

Figure 3 - Marginal effects of working in a crucial occupation on log hourly wages by major occupation groups

(Note: Estimates are based on linear regression models. Model C includes all ind.-level controls and a three-way interaction between the crucial occupation dummy, the occupation group categories, and year as a continuous variable. We model linear time trends to ensure a sufficient number of observations per estimate. Model D controls additionally for ISCO08 industry categories.) 


\section{Appendix 1 - Translated government list of crucial occupations}

- Healthcare, Youth Assistance and (Social) Support, including production and transportation of medicines and medical devices

- $\quad$ Teachers and staff needed at school, such as for distance learning, childcare and exams

- Public transport

- Food chain: the food chain must be viewed in a broad sense. This consists of supermarkets, the supply of supermarkets, the processing industry and the transport of this industry, but also the collection of products from farmers, the delivery of, for example, animal feed and other products to farmers, the access of workers for the harvest

- Transport of fuels such as coal, oil, petrol and diesel, et cetera

- $\quad$ Transport of waste and garbage

- Day-care

- Media and communication: for the provision of information to society, which is essential to keep the population informed

- Continuity of emergency services (police and defense have already been declared vital): firefighting processes, ambulant care, GHOR, crisis management of the regions, necessary government processes (central government, province and municipality) (payment of benefits and allowances, civil affairs, consulates and embassies)

For the Netherlands, companies have always had processes that have been designated as vital. It concerns approximately 100 companies that are already aware of this:

- $\quad$ Rural / regional transport and distribution of electricity

- Gas production, rural / regional transport and distribution

- Oil supply

- Internet and data services; ICT / Telecom, Internet access and data traffic Voice service and SMS

- $\quad$ Location and time determination using GNSS

- Drinking water supply; reversing and managing water quantity

- Flight and aircraft handling

- $\quad$ Shipping settlement

- $\quad$ Large-scale production / processing and / or storage of (petro) chemicals

- Storage, production and processing of nuclear material

- $\quad$ Point-of-sale payments; massive cashless payments; high-quality payments between banks; securities transactions

- Communication with and between emergency services via 112 and C2000

- Deployment of the police

- $\quad$ Basic registers of persons and organizations; digital government processes

- Interconnectivity (transaction infrastructure for information from key registers); electronic messaging and information provision to citizens

- Identification and authentication of citizens and companies

- Defense deployment 


\section{Appendix 2 - Coding scheme of crucial occupations}

Step 1: Initial rough identification based on BRC

BRC codes 11211311413143562163163263363475175210111012101310211022103110321033 $103410351041105112131214121512211222(+)$

Step 2: Add complete industry categories healthcare and nursing / care with overnight stay

SBI codes $8687(+)$

Step 3: Remove several occupations based on ISCO08 to refine step 1

ISCO08 codes 2250226626362632263332403411341322308300834083418342834383448350 (-)

Step 4: Add several occupations based on ISCO08 to refine step 1

ISCO08 codes 61106111611261136120612161226123613062216222921192129213921492159216 $(+)$

Step 5: Add sales workers, but select only if working in supermarkets, pharmacies, drug stores, medical stores BRC codes 331332333 if (SBI == $47110|47730| 47740|47741| 47742)(+)$

Step 6: Refine the selection within BRC 1222 garbage collectors (remove specific ISCO08 categories within BRC 1222)

BRC codes 1222 if (ISCO08 ==9510|9520|9613|9621|9622|9623|9629) (-)

Step 7: Refine selection of legal workers

ISCO0826112612 $2619(-)$

Step 8: Adjustments on the basis of the processes defined as vital

ISCO08 code 4223 if SBI code $84(+)$

SBI codes 06100620191019201351135123513351461106120613084399 (+)

ISCO08 codes $264226542656351135123513(+)$ 